\title{
GRAVITY DATA ANALYSIS IN BOGOR WESTJAVA - INDONESIA
}

\author{
Andi Agus Nur \\ Faculty of Geological Engineering, Universitas Padjadjaran, Indonesia
}

\begin{abstract}
Gravity measurements have been conducted, 169 gravity measurement data points with varied heights at each measuring point from 16 to 595.1 meters above sea level which is divided into two measurement paths. With the distance between the measuring points at a certain variation interval (effective 750 meters), using a closed loop method that aims to map subsurface conditions to Identifiying Structural Geology in the Bogor, West Java-Indonesia region. Complete Bouguer Anomaly (CBA) values varies from $26 \mathrm{mGal}$ to $66 \mathrm{mGal}$. The High Anomalous Area, has a value of $>46 \mathrm{mGal}$, occupies more than the southern half of the study area, extends in the southwest to the possibility of symmetry in the east, and there is the highest anomaly between them. This high anomaly area is produced by a rock mass that has a greater mass density $\left(\geq 2.507647059 \mathrm{gr} / \mathrm{cm}^{3}\right)$. The Low Anomaly Area, has a value of $\leq 46 \mathrm{mGal}$, occupying less than half of the research area in the north. Increasing the anomaly value in the north on the map, forming an indication pattern of an open basin. This low anomaly area is produced by a rock mass which has a lower mass density $\left(\leq 2.507647059 \mathrm{gr} / \mathrm{cm}^{3}\right)$. Rock density at the study area based on forward modeling shows values in the range of $1.8 \mathrm{gr} / \mathrm{cm}^{3}$ s.d. $2.67 \mathrm{gr} / \mathrm{cm}^{3}$. The results of the study using gravity method based on $2 \mathrm{D}$ cross section shows that the main fault in bedrock along the AA 'research path is relatively West - East, with stratigraphic direction of each constituent rock layer to the south. The direction of the fault forms block faulting, making this area graben.
\end{abstract}

Keywords: Structural Geology, Graben, Gravity, Density

\section{Introduction}

This study uses gravity data analysis to determine the subsurface structure of the fault pattern which is focused on the research path (cross section) located along the coordinates $6.636^{\circ} \mathrm{LS}$ and $107.000^{\circ}$ 107.2438 ${ }^{\circ}$ East, Cianjur.

This was done because there was no insight geophysical geological survey on the trajectory so that the information in the area was quite limited. The cross section is quite unique, because it is suspected that there is a structural pattern of normal fault blocks in the form of expansion faults, in addition to general review that the area is composed of volcanic rocks and sedimentary rocks.

The interpretation of the number of complex fault structure patterns is thought to be one of the control of hydrocarbon manifestations and cause a high rock density contrast, especially those below the surface in the cross section. 
The results of the study are expected to provide information about subsurface structures along the research path (cross section) and can be used as information analysis in geodynamic studies in the study area.

The primary purpose of the research is to identify the regional condition of the subsurface, such as the the stratigraphic unit of formation in study area and identify the geological structure.

\section{Methods}

Data collection is done throughout the study area, with points that resemble the track grid as shown in figure 2,[9]. These paths are selected to determine the subsurface sections produced in the research location.

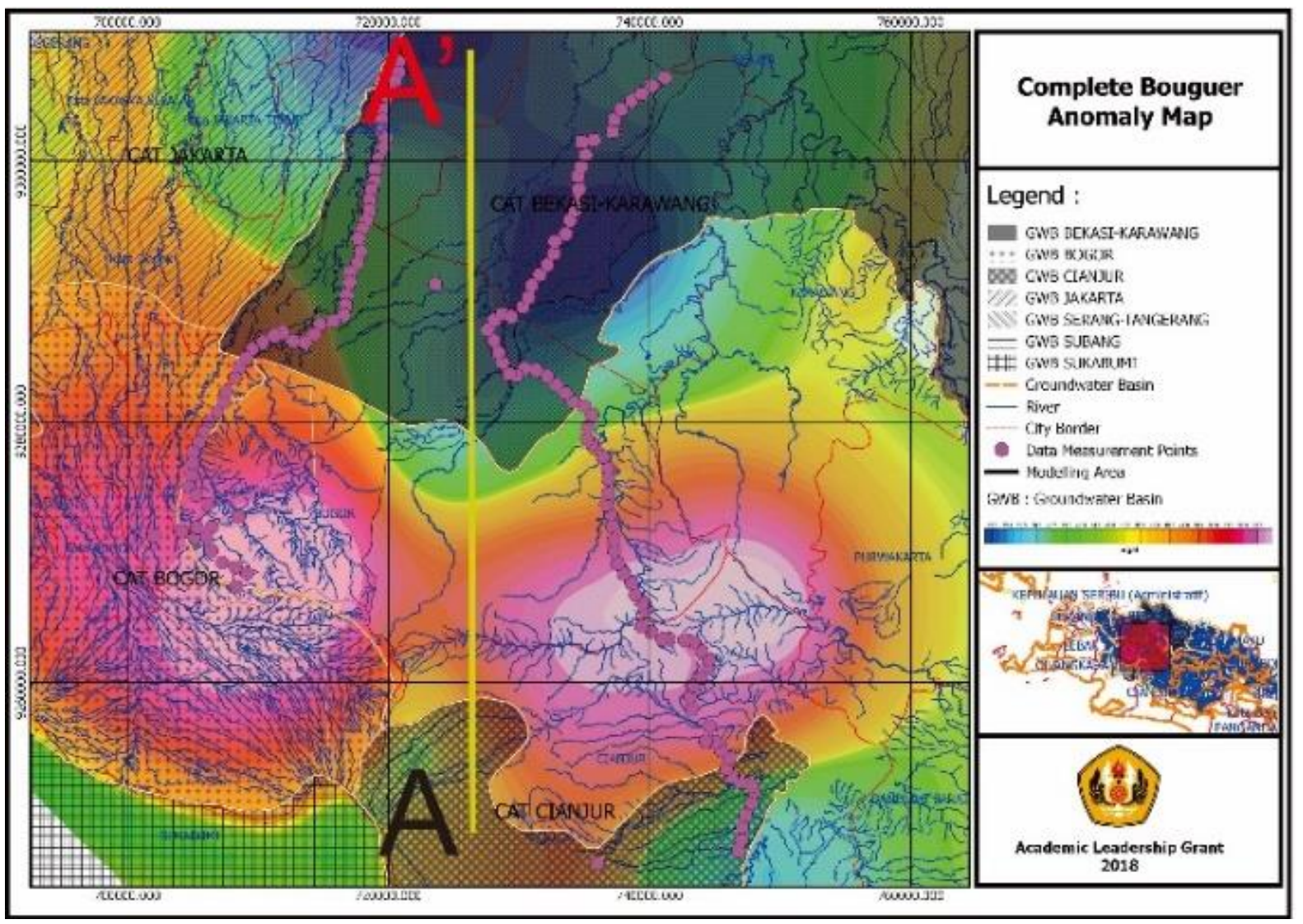

Fig. 2 Gravity Data Acquisition Datum Point

After obtained the necessary data, then performed data processing. Processing on gravity data is done by performing correction on field data that has been obtained. Further analysis is done using Oasis Montaj software. 


\section{Result and Discussion}
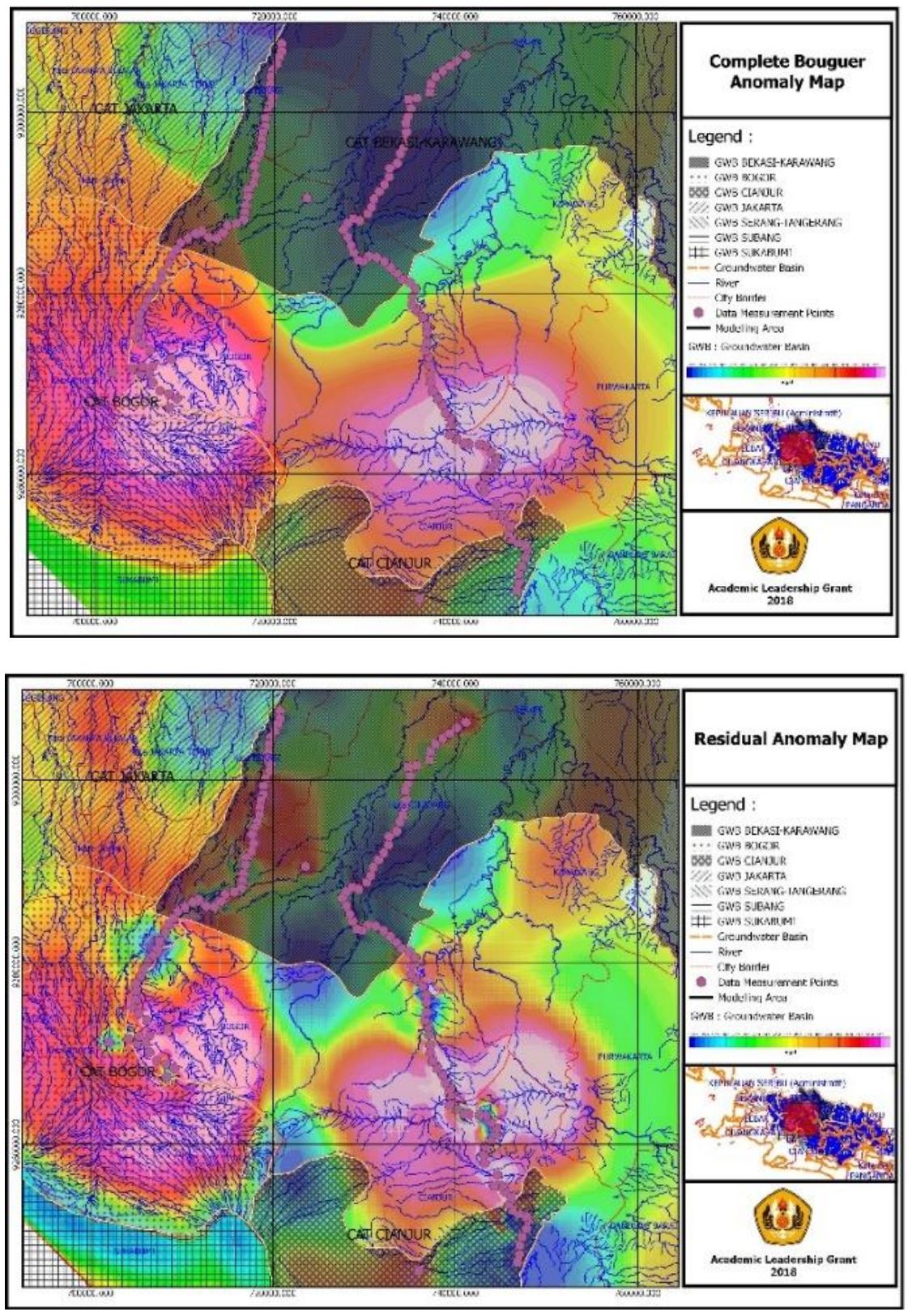

Fig. 3. Complete Bouguer Anomaly and Residual Anomaly map of Study Area

This complete Bouguer anomaly map is divided into two groups of anomalies based on their density range. The first group, namely high anomaly, occupies the southern part of the sheet, while the second group is the low anomaly occupying the northern part of the complete anomaly map. A large elliptical spherical anomaly group centered around the coordinates of the measuring data 6.673567 LS; 107,212183 BT (measuring point CR21) with a maximum value reaching $63.75311773 \mathrm{mGal}$ and 6.61555 LS; $106.89185^{\circ}$ East (measuring point $\mathrm{BC61}$ ) with a range of $\mathrm{AB}$ values ranging from 64.55761115 s.d. $66 \mathrm{mGal}$. The second anomaly group, in the form of anomalous lanes with a minimum slope of around 260. 27,41380021 mGal located on the southern part of the map sheet, centered around the coordinates 6.3844 LS; $107.1041^{\circ}$ East (measuring point CR71). The anomaly pattern provides an overview of the subsurface anomalous structures found at the location of the study this time. 
On this Bouguer anomaly map, the anomalies that appear to be too obvious are observed, so it is better to be assisted with a residual map. The residual anomaly map (upward result) is the display of data resulting from the reduction of Complete Bouguer Anomaly data (which is a combination of shallow and deep gravity anomaly response) to regional anomaly data so that the effect / response of the residual anomaly can be observed.

The High Anomalous Area, has a value of $>46 \mathrm{mGal}$, occupies more than the southern half of the study area, extends in the southwest to the possibility of symmetry in the east, and there is the highest anomaly between them. This high anomaly area is produced by a rock mass that has a greater mass density $\left(\geq 2.507647059 \mathrm{gr} / \mathrm{cm}^{3}\right)$.

The Low Anomaly Area, has a value of $\leq 46 \mathrm{mGal}$, occupying less than half of the research area in the north. Increasing the anomaly value in the north on the map, forming an indication pattern of an open basin. This low anomaly area is produced by a rock mass that has a lower mass density ( $\leq$ $\left.2.507647059 \mathrm{gr} / \mathrm{cm}^{3}\right)$.

The results of the 2D forward modeling using GMSys Oasis Montaj are obtained subsurface conditions as follows (figure 7)

1. Layer with $1.8 \mathrm{gr} / \mathrm{cm}^{3}$ density

2. This layer is thought to consist of a layer of soil, alluvium, alluvial quaternary volcanic deposits in a model of light blue cross section. this layer has a thickness of 50-100 m, found in depths of $0-50 \mathrm{~m}$.

3. Layer with Density $2.1 \mathrm{gr} / \mathrm{cm}^{3}$

4. This layer is a layer consisting of bojongmanik formations which in a dark green section, the thickness of this layer varies from $300-500 \mathrm{~m}$, this layer thickens to the north, this layer is at a depth of $50-500$

5. Layer with Density of $2.4 \mathrm{gr} / \mathrm{cm}^{3}$

6. This layer is a layer consisting of klapanunggal formations in a blue section, the thickness of this layer varies from $500-600 \mathrm{~m}$, this layer thickens to the north, this layer is at a depth of $500-1000 \mathrm{~m}$

7. Layer with Density of $2.5 \mathrm{gr} / \mathrm{cm}^{3}$

8. This layer is a layer consisting of Jatiluhur formations in an orange section, the thickness of this layer varies from $500-600 \mathrm{~m}$, this layer thickens to the north, this layer is at a depth of $1000-1500 \mathrm{~m}$

9. Layer with Density $2.67 \mathrm{gr} / \mathrm{cm}^{3}$

10. This layer is a layer consisting of a basement which in an orange section, the thickness of this layer varies greatly from $500-1000 \mathrm{~m}$, this layer thickens to the north, this layer is located at a depth of $1500-2500 \mathrm{~m}$ 


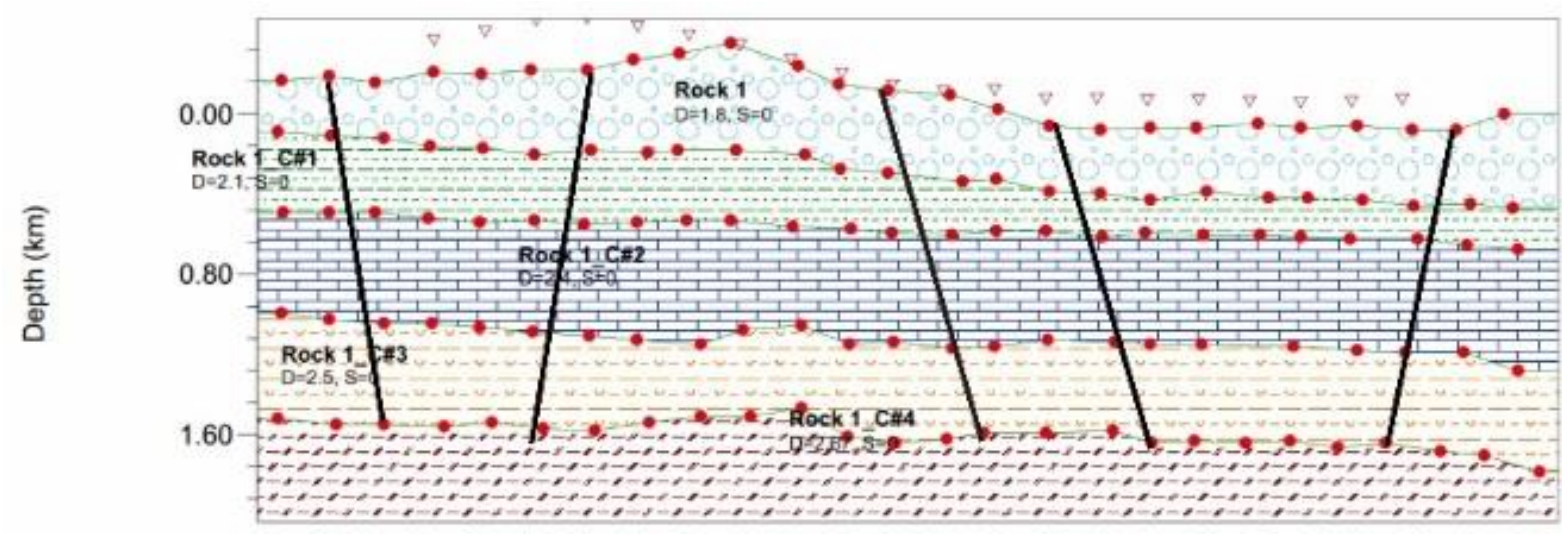

Fig 6. 2D Forward Modelling Result

Modeling results show anomalies that form normal fault fault blocks (normal / descending faults that occur due to extension or stretching force resulting in a fall to form a graben). The error factor (Vertical Exaggerration) in the AA 'cross section modeling is around 2.37 so the modeling accuracy is very good so that the accuracy of the modeling can be accounted for.

From the gravity equation given that gravity is directly proportional to the mass of the cause, mass is directly proportional to density and gravity is inversely proportional to the square of distance, it can be concluded that in that area because it has an anomaly higher than other regions along the cross section so that it has a density greater at shallow distances. The fault formation found in the modeling section (along the research path) is estimated to be related to the fault which is west - east around Gunung Gadung which is in the middle of the cross section, presumably a structure that controls geothermal manifestations as stratigraphic traps of Parigi Formation which can be hydrocarbon reservoirs.

The results of the study using gravity method based on $2 \mathrm{D}$ cross section shows that the main fault in bedrock along the AA 'research path is relatively West - East, with stratigraphic direction of each constituent rock layer to the south. The direction of the fault forms block faulting, making this area graben. Based on Bouguer anomaly maps and residual anomalies, the results of the continuation are upwards, the anomalies that appear along the research path are classified as high anomalies. This anomaly that arises is thought to be caused by the presence of material that is quite dense / compact in the area with a shallow source plus a rock layer that is relatively up and down due to fault blocks in the study area due to the impact of tectonic movements and results in a higher density than the surrounding.

Geologically, high anomalies in the trajectory of this study are also thought to be related to intrusive (andesite) rocks that contribute below the surface. The visible fracture is a normal fault due to the tectonic form of tension that has died. Based on information from previous studies, it was confirmed that the fault was thought to have cut the Parigi formation in the entire geological information on the West-East section of the North West Java Basin.

\section{Conclusion}

Geologically, high anomalies in the trajectory of this study are also thought to be related to intrusive (andesite) rocks that contribute below the surface. The visible fracture is a normal fault due to the 
tectonic form of tension that has died. Based on information from previous studies, it was confirmed that the fault was thought to have cut the Parigi formation in the entire geological information on the West-East section of the North West Java Basin.

\section{Acknowledgement}

Research Center for Geotechnology, Indonesian Institute of Sciences, Bandung for providing data and software analysis

\section{References}

Al-Khafaji WMS, Al-Dabbagh HAZ (2016) Visualizing geoelectric - Hydrogeological parameters of Fadak farm at Najaf Ashraf by using 2D spatial interpolation methods. NRIAG J Astron Geophys 5:313-322. https://doi.org/https://doi.org/10.1016/j.nrjag.2016.07.001

Araffa SAS, El-bohoty M, Abou Heleika M, et al (2018) Implementation of magnetic and gravity methods to delineate the subsurface structural features of the basement complex in central Sinai area, Egypt. NRIAG J Astron Geophys 7:162-174. https://doi.org/https://doi.org/10.1016/j.nrjag.2017.12.002

Basheer, A., Mansour, K., \& Abdalla, M. 2014. Geophysical investigation to reveal the groundwater condition at new Borg El-Arab industrial city, Egypt. NRIAG Journal of Astronomy and Geophysics 3 : 117-129.

Bayewu, O. O. 2018. Assessment of groundwater prospect and aquifer protective capacity using resistivity method in Olabisi Onabanjo University campus, Ago-Iwoye, Southwestern Nigeria. NRIAG Journal of Astronomy and Geophysics vol.7 99 - 106.

Curtin, S.E., Andreasen, D.C., \& Staley, A.W. 2012. Potentiometric surface and water-level difference maps of selected confined aquifers of Southern Maryland and Maryland's Eastern Shore, 1975-2011. U.S. Geological Survey Scientific Investigations Report 2012-5165.

Sultan SA, Essa KSAT, Khalil MH, et al (2017) Evaluation of groundwater potentiality survey in south Ataqanorthwestern part of Gulf of Suez by using resistivity data and site-selection modeling. NRIAG J Astron Geophys 6:230-243. https://doi.org/10.1016/j.nrjag.2017.02.002

Helaly, A. S. 2017. Assessment of groundwater potentiality using geophysical techniques in Wadi Allaqi basin, Eastern Desert, Egypt - Case study. NRIAG Journal of Astronomy and Geophysics vol.6 408-421.

Mansour K, Omar K, Ali K, Abdel Zaher M (2018) Geophysical characterization of the role of fault and fracture systems for recharging groundwater aquifers from surface water of Lake Nasser. NRIAG J Astron Geophys 7:99-106. https://doi.org/10.1016/j.nrjag.2018.02.001

Massoud, U., Kenawy, A., Ragab, E., Abbas, A., \& El-Kosery, H. 2014. Characterization of the groundwater aquifers at El Sadat City by joint inversion of VES and TEM data. NRIAG Journal of Astronomy and Geophysics 3 : 137-149.

Mogaji KA, Lim HS (2018) Application of Dempster-Shafer theory of evidence model to geoelectric and hydraulic parameters for groundwater potential zonation. NRIAG J Astron Geophys 7:134-148. https://doi.org/https://doi.org/10.1016/j.nrjag.2017.12.008

Mogaji, K.A. and Omobude, O. B. 2017. Modeling of geoelectric parameters for assessing groundwater potentiality in a multifaceted geologic terrain, Ipinsa Southwest, Nigeria- A GIS-based GODT approach. NRIAG Journal of Astronomy and Geophysics vol.6 $434-451$. 
Mohamaden, M. I. I. and Ehab, D. 2017. Application of electrical resistivity for groundwater exploration in Wadi Rahaba, Shalateen, Egypt. NRIAG Journal of Astronomy and Geophysics vol.6 $201-209$.

Mohamaden. 2016. Delineating groundwater aquifer and subsurface structures by using geoelectrical data: Case study (Dakhla Oasis, Egypt). NRIAG Journal of Astronomy and Geophysics vol.5 247-253.

Oni, T.E., Omosuyi, G.O., and Akinlalu A.A. 2017. Groundwater vulnerability assessment using hydrogeologic and geoelectric layer susceptibility indexing at Igbara Oke, Southwestern Nigeria. NRIAG Journal of Astronomy and Geophysics vol.7 452 - 458.

Ranganai, R. , Moidaki, M. , King, J. and Bagai, Z. (2017) Geophysical and Hydrogeological Groundwater Prospectivity Mapping in the Kraaipan Granite-Greenstone Terrain, Southeast Botswana. Journal of Water Resource and Protection, 9, 1270-1298. doi: 10.4236/jwarp.2017.911082.

Yousif M, Sabet HS, Ghoubachi SY, Aziz A (2018) Utilizing the geological data and remote sensing applications for investigation of groundwater occurrences, West El Minia, Western Desert of Egypt. NRIAG J Astron Geophys 7:318-333. https://doi.org/https://doi.org/10.1016/j.nrjag.2018.07.002 